\title{
The acceptance and use of a virtual learning environment in higher education: an empirical study in Turkey, and the UK
}

Open Access

\author{
Özlem Efiloğlu Kurt ${ }^{1 *}$ and Özhan Tingöy ${ }^{2}$
}

\author{
* Correspondence: \\ oekurt@yalova.edu.tr \\ ${ }^{1}$ Computer Programming \\ Department, Yalova University, \\ Yalova Meslek Yüksekokulu, \\ Baglarbasi M. Safranyolu C., 77100, \\ Merkez, Yalova, Turkey \\ Full list of author information is \\ available at the end of the article
}

\begin{abstract}
This study evaluated the acceptance and use of a virtual learning environment in higher education by using the unified theory of acceptance and use of technology (UTAUT) model. Study data were collected by means of a questionnaire form, completed by 1032 students receiving undergraduate education in Turkey and the United Kingdom, who currently use similar virtual learning environments. The role of performance expectancy, effort expectancy, social influence and facilitating conditions were evaluated and tested for both countries. The study results demonstrated that the behavioral intention and use behavior regarding the utilization of a virtual learning environment in higher education differed between the two countries, and that the level of impact of the factors that shape behavioral intention and use behavior also differed from one factor to another.
\end{abstract}

Keywords: Unified theory of acceptance and use of technology (UTAUT), Technology adoption, Virtual learning environment (VLE), Turkey, United Kingdom

\section{Significance statement}

While the fast progress in technology has been continuing, the transfer of improved technologies into different application fields has become a current issue. In parallel with the accelerated technological innovations, the utilization of technology in educational processes has also increased. Hence, the studies focusing on the acceptance and utilization of these technologies particularly by students have come into prominence. The key motivation of the present study, which investigates the different models dealing with the acceptance and utilization of information systems in the literature, is to determine the student acceptance and utilization of a virtual learning system based on a pre-tested model. Building on similar virtual learning systems in two public universities-one is in Turkey and the other is in the UK- this research aims to reveal the students' intentions to utilize the system and also determine similarities and differences in their behaviours in using the system.

\section{Introduction}

Parallel to the rapid developments and changes in information technologies, the application of these technologies in new areas has been a subject of considerable interest in the literature. There are numerous studies focusing on the acceptance and use of information technologies (Fishbein \& Ajzen, 1975; Davis, Bagozzi, \& Warshaw, 1989; Taylor

(C) The Author(s). 2017 Open Access This article is distributed under the terms of the Creative Commons Attribution 4.0 International License (http://creativecommons.org/licenses/by/4.0/), which permits unrestricted use, distribution, and reproduction in any medium, provided you give appropriate credit to the original author(s) and the source, provide a link to the Creative Commons license, and indicate if changes were made. 
\& Todd, 1995; Venkatesh, Morris, Davis, \& Davis, 2003; Sun \& Zhang, 2006; AlGahtani, Hubona, \& Wang, 2007; Lee, Choi, Kim, \& Hong, 2007; Im, Hong, \& Kang, 2011). These studies indicate that there are various important factors that affect the acceptance and use of information technologies by individuals belonging to different countries and cultures. These studies that began in the 1980s first made use of the Technology Acceptance Model (TAM), which is based on different social and behavioral theories, and which was gradually revised and further developed until it was finalized as the Unified Theory of Acceptance and Use of Technology (UTAUT). Although these theories have been tested in many different countries, the number of comparative studies between them is still very limited. The present study utilizes the UTAUT, an up-to-date and highly descriptive model, to demonstrate the acceptance and use of a virtual learning environment in higher education within the context of two countries (Turkey and the United Kingdom), and thereby seeks to contribute to the existing literature. In this context, the study first describes in detail the UTAUT model by providing comprehensive information on the models relating to the use and acceptance of technology, and then describes the relationships between these models. After providing information regarding the study sample and scales, the study hypotheses were tested, and the results were discussed in detail.

\section{Literature review}

As information technologies become more widespread around the world and in every possible area of use, there has also been a growing interest on how technology is perceived, accepted and used by individuals. Whether technologies that originate from a single centre will be equally accepted by different societies with different beliefs, values, approaches, and even physical characteristics, and whether these technologies will be used with the same content and in the same function across different societies and present satisfying ergonomics, are important questions that are subject to considerable debate. There are various studies in the literature attempting to answer these questions, which have mainly focused on behavioral models. In this context, a number of different models regarding the acceptance and use of technology have been proposed and tested. Among these different models, the ones most frequently used within the frame of various studies are the Theory of Reasoned Action, the Theory of Planned Behavior, the Innovation Diffusion Theory, and the Unified Theory of Acceptance and Use of Technology (Raaij \& Schepers, 2008; Martinez-Torres et al., 2008; Wang, Wu, \& Wang, 2009; Al-Senaidi, Lin, \& Poirot, 2009; Premkumar, Ramamurthy, \& Liu, 2008; Usluel, Aşkar, \& Baş, 2008). The first model on the acceptance of technology to be developed in the literature is the Theory of Reasoned Action (TRA). Initially developed in 1980, it has been revised many times since, eventually becoming its current and most comprehensive version in 2003, as the UTAUT.

One of the most fundamental theoretical models in the literature concerning the acceptance of technology is the TRA developed in 1980 by Icek Ajzen and Martin Fishbein (Sheppard, Hartwick, \& Warshaw, 1988, p. 325). The foundations of this theory are based on social psychology. The theory is also an extension of Dulany's Theory of Propositional Control. Dulany (1967) argued that an individual's behavior is the product of his/her behavioral intention (Ajzen \& Fishbein, 1969, p. 400; Ajzen \& Fishbein, 1970, p. 466). According to the TRA, the behaviors of individuals are 
influenced by their attitudes towards the outcomes of their behaviors, as well as the opinions of other individuals within their social environment. According to Ajzen and Fishbein, the TRA is a psychological process model that mediates the observed relationship between behavior and attitude (Ajzen \& Madden, 1986). The Theory of Planned Behavior (TPB), which is based on the TRA, is built on the assumption that humans generally act in a rational way by taking all available information into account and observing the consequences of their behaviors. TPB was put forward by Ajzen in 1985 as an extension of the TRA that also sought to resolve its shortcoming (Ajzen, 1985 p. 11; Ajzen \& Madden, 1986, p. 456). According to the TPB, an individual's intention in performing or avoiding a certain behavior is the most important determinant of whether that behavior is exhibited (Ajzen, 2005, p. 117). The Innovation Diffusion Theory (IDT), which is a sociology-based theory, traces its roots back to the 1960s (Rogers \& Shoemaker, 1971; Tornatzky \& Klein, 1982, p. 29). The concept of diffusion has been extensively studied in the fields of sociology, economy, politics, and communication. These studies are based on Tarde's work entitled "The Laws of Imitation," published in 1903. Roger's work entitled "Diffusion of Innovations," which was first published in 1962, includes citations from Tarde. Studies on diffusion have been conducted in many different fields such as agricultural applications, technology, reproduction control methods, politics, and political reforms with the aim of defining the process, principles, and components of diffusion under different circumstances (Wejnert, 2002, p. 298). IDT was put forward by Everett M. Rogers to examine the factors that influence the diffusion of innovation by taking into account the perception of individuals, as well, and to analyze how innovation (or the "new") can be disseminated in social systems through communication. In other words, IDT evaluates the factors that affect diffusion by taking individual perceptions into consideration, and examines how innovation is diffused through communication processes within social systems.

The Technology Acceptance Model (TAM), which is one of the most widely used models in the literature, was first proposed by Fred D. Davis in 1985 within the frame of his doctorate thesis as a model for testing and developing user acceptance of computer-based information systems (Davis, 1985). The aim of this model is to form a theoretical basis for explaining within a broad context the determinants involved in the acceptance of computer technologies, and the end user behaviors towards computer technologies. The model has found widespread acceptance by researchers and users, since it not only permits the prediction of the reasons why a certain system may fail to find acceptance, but also assists in explaining these reasons and determining corrective action (Srite, Thatcher, \& Galy, 2008, p. 3). According to Davis et al. (1989), p. 985, the purpose of the model is to provide a general model for predicting and explaining the use of communication technologies. TAM explains the beliefs, behaviors, and intentions of users with regards to communication technologies based on a theoretical construct. TAM assumes that the acceptance of technologies by individuals is primarily dictated by two factors, which are the perceived usefulness and perceived ease of use (Davis, 1989, p. 320; Lee, Kozar, \& Larsen, 2003, p. 752). Perceived usefulness and perceived ease of use with computer-based information systems have also been subject to considerable study by management and behavioral researchers (Schewe, 1976, p. 577; Robey, 1979, p. 527; Davis, 1989, p. 319). In addition to the TAM he proposed, Davis (1985), p. 25 also described various external variables. The most commonly described 
variables in the literature include system quality, training, computer anxiety (Igbaria, Guimaraes, \& Davis, 1995a), self-efficacy (Igbaria, Livari, \& Maragahh, 1995b), enjoyment (Igbaria et al., 1995b), compatibility (Chau \& Hu, 2001), accessibility, support and experience (Chau, 1996). TAM is a theory that measures the users' willingness and intent to use a certain technology based on certain factors. The theory has been occasionally criticized for being limited in scope, and researchers have attempted to improve the theory's descriptive power by adding different elements. However, despite all the criticism it has drawn, TAM has become one of the most valid models in the literature evaluating the acceptance of technology at an individual level, and is one of the most widely accepted behavioral models in the field of information technologies (Legris, Ingham, \& Collerette, 2003, p. 202; McCoy, Galetta, \& King, 2007, p. 81; Turan \& Çolakoğlu, 2008, p. 112). Since it was first developed, TAM underwent various changes. As such, different alternatives of the model were developed, and based on the criticism it received, various studies were conducted to reduce the limitations of the model. In 2000, Venkatesh and Davis developed the Technology Acceptance Model 2 (TAM2), which, in addition to being a synthesis of previous studies on the TAM, sought to remedy some of the criticized aspects of the model. The model clearly takes into account the external variables of perceived usefulness and perceived ease of use. In this context, Venkatesh and Davis defined the external variables of perceived usefulness, such as social effect and cognitive tools. When recent developments are considered, it is possible to see that TAM has constantly evolved since it was first proposed. As a result of this evolution, TAM was followed by TAM2, and later by Technology Acceptance Model 3 (TAM3) in the literature (Venkatesh \& Davis, 2000; Venkatesh \& Bala, 2008).

To further build upon the progress made with previous studies on the TAM, Venkatesh et al. (2003) developed the UTAUT model. The UTAUT focuses on the intent to use and the use behavior of users towards information technologies, placing emphasis on four main determinants of the intention to use and use behavior (Venkatesh et al., 2003). These determinants include performance expectancy, effort expectancy, social influence, and facilitating conditions Performance expectancy, which is the first component of the UTAUT, can be defined as the individual's beliefs regarding the benefit he/she will draw from using a system. Effort expectancy can be defined as the ease of using a particular system. Social influence can be defined as the importance an individual accords to the opinions of other regarding his/her use of a new system. Studies in the literature emphasize that performance expectancy (Venkatesh et al., 2003; Al-Gahtani et al., 2007; Taiwo \& Downe, 2013; Kaba \& Touré, 2014), effort expectancy (Venkatesh et al., 2003; Chiu \& Wang, 2008; Diño \& de Guzman, 2015), and social influence (Venkatesh et al., 2003; Taiwo \& Downe, 2013) are important factors in predicting behavioral intention. The hypotheses proposed in this study concerning the factors that affect behavioral can be listed as follows:

H1: Performance expectancy has a positive impact on behavioral intention.

H2: Effort expectancy has a positive impact on behavioral intention.

H3: Social influence has a positive impact on behavioral intention.

Facilitating conditions can be defined as the individual's belief in the availability of the necessary organizational and technical infrastructure for enabling the use of a 
system. Studies in the literature emphasize that facilitating conditions have an effect on use behavior rather than behavioral intention (Venkatesh et al., 2003; Chiu \& Wang, 2008; Wang \& Shih, 2009; Taiwo \& Downe, 2013). Similarly, another factor that affects use behavior is behavioral intention (Venkatesh et al., 2003; Lin \& Anol, 2008; Zaremohzzabieh, Samah, Omar, Bolong, \& Mohamed Shaffril, 2014; Hou, 2014). The hypotheses proposed in this study concerning the factors that affect use behavior can be listed as follows:

H4: Facilitating conditions have a positive impact on use behavior.

H5: The users' behavioral intention has a positive impact on use behavior.

Various studies in the literature emphasize that there are differences between countries with regards to the acceptance and use of different technologies (Sun \& Zhang, 2006; Lee et al., 2007; Al-Gahtani et al., 2007; Im et al., 2011). The hypotheses put forward in this study concerning the differences between countries can be listed as follows:

H6: There is a difference in VLE using intentions of users from two countries.

H7: There is a difference in VLE use behavior of users from two countries.

In the UTAUT model, the gender, age, experience, and willingness variables are used to describe the effect of performance expectancy, effort expectancy, social influence, and facilitating conditions on behavioral intention and use behavior (Venkatesh et al., 2003). There are various studies in the literature where these variables are not included into the study model (Sumak, Polančič, \& Heričko, 2010; Im et al., 2011; Nistor, Lerche, Weinberger, Ceobanu, \& Heymann, 2014; Magsamen-Conrad, Upadhyaya, Joa, \& Dowd, 2015). As such, the effect of these variables was similarly not included into our study model. The study model used for testing the study hypotheses is shown in Fig. 1.

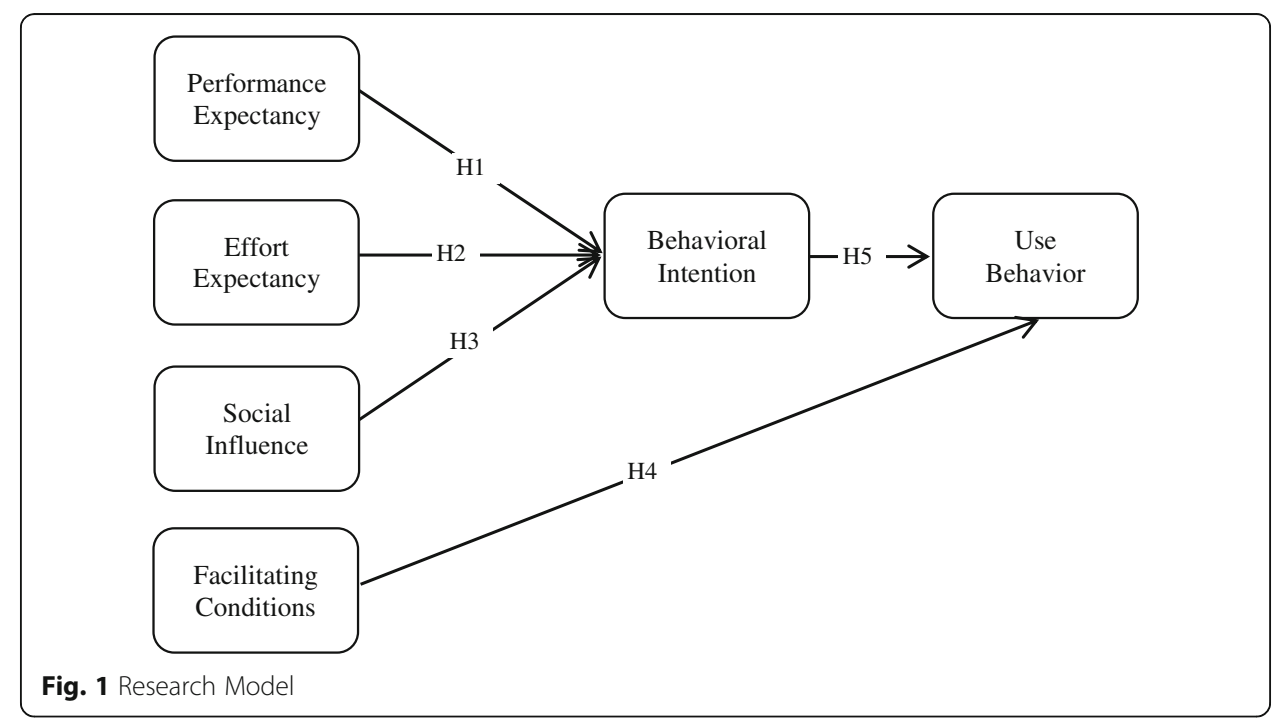




\section{Methods}

Data collection and study sample

The necessary data for testing the study hypotheses were collected using a questionnaire-based method. Previous studies on the acceptance of technology were examined in order to prepare questionnaire items for this study. When preparing the questionnaire, the dimensions and expressions used for describing the acceptance of technology were obtained from the study of Venkatesh et al. (2003), the developers of the UTAUT model. The questionnaire items were prepared in two languages, Turkish and English, and presented to the respondents in their respective languages. The questionnaire form prepared in English was reviewed by three native English speaking academicians, and the form was finalized based on the changes they recommended. A similar approach was followed for the Turkish questionnaire, which was also finalized based on the views of three academicians.

The study sample consisted of 522 undergraduate students at Leeds University in the United Kingdom using the Virtual Learning Environment (VLE), and 510 undergraduate students at Sakarya University in Turkey using the Educational Information System (EIS). The questionnaires completed by these students were included in the study analysis. The reason for choosing the University of Leeds for this study is for two reasons. First, the related technology has been frequently used at their undergraduate level education. Second is having access to the university during the data collection process. The rationale for choosing Sakarya University from Turkey is that they have more experience than many other Turkish universities in using information technologies for educational purpose and the virtual learning environment they use is quite similar with the one used in the University of Leeds.

\section{Sample characteristics}

The descriptive results of the study were evaluated by using the frequency distributions of the participants' demographic characteristics. To ensure that the study results would better shed light on the analyses that will be performed in the following sections of the manuscript, the results for Turkey and the United Kingdom were divided and presented separately on the study tables.

\section{Results and Discussion}

\section{Testing the validity and reliability of the scales}

Exploratory factor analysis (EFA) was performed for both data sets. The Alpha model was used for performing reliability analyses. Tables 1 and 2 summarizes the factor analysis performed on the data set from Turkey, and also show the factor loads of the questionnaire items and the Cronbach's alpha coefficients of the variables. Cronbach's alpha coefficients ranged between 0.82 and 0.90 , indicating that the factor had fairly high reliability.

Table 3 illustrates the correlation coefficients between the variables in the samples from Turkey and the United Kingdom.

\section{Testing of the hypotheses}

A regression analysis was used to determine the effect of social influence, performance expectancy, effort expectancy, and facilitating conditions variables that were determined 
Table 1 Demographics of survey respondents

\begin{tabular}{lllll}
\hline & $N$ & & $\%$ & UK \\
\cline { 2 - 4 } & TR & UK & TR & 37.5 \\
\hline Age & 20 & 196 & 3.9 & 47.5 \\
$20-19$ & 203 & 248 & 39.8 & 14.9 \\
22 and up & 287 & 78 & 56.3 & 100.0 \\
Total & 510 & 522 & 100.0 & \\
Gender & & & & 45.2 \\
Male & 293 & 236 & 57.5 & 54.8 \\
Female & 217 & 286 & 42.5 & 100.0 \\
Total & 510 & 522 & 510 & \\
Internet Access & & 520 & 80.6 & 99.6 \\
Yes & 411 & 2 & 19.4 & 0.4 \\
No & 99 & 522 & 100.0 & 100.0 \\
Total & 510 & & & \\
\hline
\end{tabular}

Note: TR Turkey, UK United Kingdom

through factor analysis on the behavioral intention and use behavior variables. In accordance with the study model, multi-linear regression was applied to both data sets to observe the effect of performance expectancy, effort expectancy, and social influence on behavioral intention. In the model including the performance expectancy, effort expectancy, and social influence variables, the F value for the data set from Turkey was 107.509

Table 2 Factor analysis results and Cronbach's alpha coefficients

\begin{tabular}{|c|c|c|c|c|}
\hline \multirow[t]{2}{*}{ Measurement Items } & \multicolumn{2}{|c|}{ Factor Loads } & \multicolumn{2}{|c|}{ Cronbach's a } \\
\hline & TR & UK & TR & UK \\
\hline Performance expectancy & & & .89 & .83 \\
\hline I find the VLE useful in my studies. & .770 & .646 & & \\
\hline Using the VLE enables me to accomplish tasks quickly. & .751 & .767 & & \\
\hline Using the VLE increases my productivity in lectures. & .831 & .714 & & \\
\hline If I use the VLE, I will increase my productivity in lectures. & .811 & .714 & & \\
\hline Effort expectancy & & & .87 & .89 \\
\hline I find the VLE easy to use & .679 & .620 & & \\
\hline Learning to operate the VLE is easy to me. & .693 & .630 & & \\
\hline Social influence & & & .76 & .79 \\
\hline My classmates think that I should use the VLE. & .693 & .688 & & \\
\hline My lecturers have been helpful in the use of the VLE. & .671 & .637 & & \\
\hline In general, my university has supported the use of the VLE. & & .646 & & \\
\hline Facilitating conditions & & & .84 & .86 \\
\hline I have the resources necessary to use the VLE. & .775 & .804 & & \\
\hline I have the knowledge necessary to use the VLE. & .817 & .858 & & \\
\hline Behavioral intention & & & .92 & .98 \\
\hline I intend to use the VLE in future modules. & .792 & .906 & & \\
\hline I predict I will use the VLE in future modules. & .769 & .916 & & \\
\hline I plan to use the VLE in future modules. & .758 & .916 & & \\
\hline
\end{tabular}


Table 3 Intercorrelations between the variables

\begin{tabular}{|c|c|c|c|c|c|}
\hline & Use & $\mathrm{PE}$ & $\mathrm{EE}$ & $\mathrm{SI}$ & FC \\
\hline \multicolumn{6}{|l|}{ Turkey } \\
\hline Use & 1 & & & & \\
\hline PE & $.313^{* *}$ & 1 & & & \\
\hline $\mathrm{EE}$ & $.351^{* *}$ & $.661^{* *}$ & 1 & & \\
\hline $\mathrm{SI}$ & $.269^{* *}$ & $.513^{* *}$ & $.406^{* *}$ & 1 & \\
\hline FC & $.410^{* *}$ & $.464^{* *}$ & $.596^{* *}$ & $.422^{* *}$ & 1 \\
\hline $\mathrm{Bl}$ & $.252^{* *}$ & $.531^{* *}$ & $.503^{* *}$ & $.520^{* *}$ & $.519^{* *}$ \\
\hline \multicolumn{6}{|c|}{ United Kingdom } \\
\hline Use & 1 & & & & \\
\hline PE & $.414^{* *}$ & 1 & & & \\
\hline EE & $.294^{* *}$ & $.478^{* *}$ & 1 & & \\
\hline $\mathrm{SI}$ & $.371^{* *}$ & $.654^{* *}$ & $.471^{* *}$ & 1 & \\
\hline FC & $.229^{* *}$ & $.322^{* *}$ & $.429^{* *}$ & $.371^{* *}$ & 1 \\
\hline $\mathrm{Bl}$ & $.406^{* *}$ & $.561^{* *}$ & $.371^{* *}$ & $.503^{* *}$ & $.356^{* *}$ \\
\hline
\end{tabular}

Note: $P E$ performance expectancy, $E E$ effort expectancy, $S /$ social influence, $F C$ facilitating conditions, $B I$ behavioral intention

with $p<0.01$, while the $\mathrm{F}$ value for the data set from the United Kingdom was 94.272 with $p<0.01$. Both $\mathrm{F}$ values were statistically significant within the frame of the regression model. An evaluation of the adjusted $\mathrm{R}^{2}$ values indicated that the model explained $39 \%$ of the variance in the sample from Turkey, and $35 \%$ of the variance in the sample from the United Kingdom. Table 4 provides the beta coefficients and significance levels concerning the effect of the variables.

The effect of the performance expectancy on behavioral intention was significant in both the samples from Turkey $(\beta=0.217, p<0.01)$ and the United Kingdom $(\beta=0.379$, $p<0.01)$. This finding indicated the validity of the $\mathrm{H} 1$ hypothesis. A comparison of the results for both countries indicated that performance expectancy had a stronger effect on behavioral intention in the United Kingdom sample. An evaluation of the effect of effort expectancy on behavioral intention revealed a significant effect at a p level of 0.01 for the sample in Turkey $(\beta=0.246)$, and a significant effect at a p level of 0.05 for the sample in the United Kingdom $(\beta=0.089)$. These findings indicated the validity of

Table 4 Regression analysis results

\begin{tabular}{|c|c|c|c|c|c|c|}
\hline \multicolumn{2}{|c|}{ Model } & \multicolumn{2}{|c|}{ Unstandardized Coefficients } & \multirow{2}{*}{$\begin{array}{l}\text { Standardized Coefficients } \\
\text { Beta }\end{array}$} & \multirow[t]{2}{*}{$\mathrm{t}$} & \multirow[t]{2}{*}{ Sig. } \\
\hline & & B & Std. Error & & & \\
\hline \multirow[t]{4}{*}{ TR } & (Constant) & .958 & .180 & & 5.314 & .000 \\
\hline & Performance expectancy & .231 & .053 & .217 & 4.367 & .000 \\
\hline & Effort expectancy & .251 & .048 & .246 & 5.276 & .000 \\
\hline & Social influence & .298 & .041 & .301 & 7.339 & .000 \\
\hline \multirow[t]{4}{*}{ UK } & (Constant) & 1.146 & .268 & & 4.280 & .000 \\
\hline & Performance expectancy & .475 & .061 & .379 & 7.842 & .000 \\
\hline & Effort expectancy & .117 & .054 & .089 & 2.159 & .031 \\
\hline & Social influence & .267 & .060 & .214 & 4.443 & .000 \\
\hline
\end{tabular}

Dependent Variable: Behavioral Intention (TR)

$R=0.628 ;$ Adjusted $\mathrm{R}^{2}=0.391 ; F=107.590 ; p=0.000$

Dependent Variable : Behavioral Intention (UK)

$R=0.594 ;$ Adjusted $\mathrm{R}^{2}=0.349 ; F=94.272 ; p=0.000$ 
the $\mathrm{H} 2$ hypothesis. An evaluation of the beta coefficients indicated that the effort expectancy variable had a more prominent effect on the sample in Turkey. The analysis results demonstrated that the social influence variable had a significant effect on behavioral intention in both the samples in Turkey $(\beta=0.301, p<0.01)$ and in the United Kingdom, thus indicating the validity of the $\mathrm{H} 3$ hypothesis. A comparison of the results for the samples in Turkey and the United Kingdom showed that in Turkey, social influence is the variable that has the most significant effect on the intention to use a new system.

In the following stage, a multi-linear regression analysis was used to test the $\mathrm{H} 4$ and H5 hypotheses. In the model where facilitating conditions and behavioral intention were included as independent variables, the data set for Turkey had an F value of 48.702 and a p value $<0.01$, while the data set for the United Kingdom had an F value of 54.347 and a $\mathrm{p}$ value $<0.01$. These results indicated that the regression models were statistically significant. Adjusted $\mathrm{R}^{2}$ values, which indicate the explanatory power of the regression model, were 0.165 for the sample in Turkey, and 0.170 for the sample in the United Kingdom. This shows that the model explained $16 \%$ of the variance in the use behavior observed in the Turkey sample, and $17 \%$ of the variance in the use behavior observed in the United Kingdom sample. Table 5 provides the beta coefficients and significance levels concerning the effects of the variables.

According to the analysis results, the effect of the facilitating conditions variables on the use behavior was significant in both samples from Turkey $(\beta=0.377, p<0.01)$ and the United Kingdom $(\beta=0.097, p<0.05)$. This indicated the validity of the H4 hypothesis. An evaluation of the coefficients related to the effect of behavioral intention on use behavior revealed a significant effect for the sample in the United Kingdom $(\beta=0.372, p<0.01)$, while the same effect was not significant for the sample in Turkey $(p>.05)$. For this reason, the $\mathrm{H} 5$ hypothesis was partially supported. An evaluation of the coefficients in Table 3 indicated a moderate and significant relationship between behavioral intention and use behavior for the sample in Turkey, and that when the facilitating conditions variable was added to the regression model, the strong effect of this variable masked the relationship between intention and behavior. A general evaluation of the regression model results indicated that in the sample from the United Kingdom, use behavior was predominantly determined by behavioral intention and consequently by performance expectancy, effort expectancy, and social influence - which are the antecedents of behavioral intention. In

Table 5 Regression analysis results

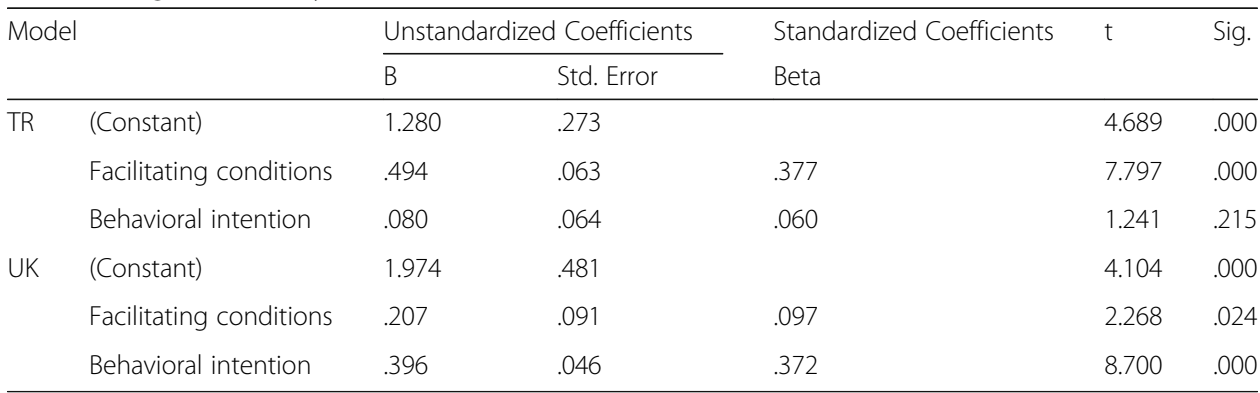

Dependent Variable : Use Behavior (TR)

$R=0.411 ;$ Adjusted $R^{2}=0.165 ; F=48.702 ; p=0.000$

Dependent Variable : Use Behavior (UK)

$R=0.416 ;$ Adjusted $R^{2}=0.170 ; F=54.347 ; p=0.000$ 
contrast, the sample in Turkey showed that facilitating conditions played a more predominant role than behavioral intention and its antecedents.

In the following stage, the T-test was applied to test the $\mathrm{H} 6$ and $\mathrm{H} 7$ hypothesis, which predicted differences with regards to the levels of behavioral intention and use behavior. The relevant results are shown in Tables 6 and 7. According to these results, there was a significant difference $(p<0.01)$ between the mean behavioral intention for the sample in Turkey (mean $=3.99$ ) and the mean behavioral intention for the sample in the United Kingdom (mean = 5.18), which supported the validity of the H6 hypothesis. A similarly significant difference was also identified between the mean values of the use behavior (Turkey sample mean $=3.69$; United Kingdom sample mean $=5.18, p<.01$ ), thus confirming the validity of the $\mathrm{H} 7$ hypothesis. Although this was not required by any of the study hypotheses, a comparison was performed between behavioral intention and the antecedents of use behavior in order to obtain more detailed information. These relevant results are shown in Table 6 .

\section{Conclusion}

In the present-day world, where technology is rapidly developing and influencing every aspect of society, one of the most intensely studied subjects is the technology adoption. Technology adoption and use of technology is an essential subject for nearly all areas and actors, from private businesses to public institutions, and from the health sector to the education sector. Numerous studies have been conducted on this subject, and a number of models that mainly attempt to describe technology adoption on an individual basis have been developed. Various models were developed in the literature based on social and behavioral theories, starting with the TAM, which was theoretically revised and further developed to obtain the UTAUT. These models have sought to explain the diffusion of certain technologies and their related applications. In this study, which aimed to demonstrate the acceptance and use of a virtual learning environment in higher education through a comparative approach, a total of 1032 undergraduate students from two samples in

Table 6 Group statistics

\begin{tabular}{llllcc}
\hline \multirow{4}{*}{ use behavior } & & $N$ & Mean & Std. Deviation & Std. Error Mean \\
perf_mean & TR & 486 & 3.69 & 1.963 & 0.089 \\
& UK & 522 & 5.18 & 1.329 & 0.058 \\
effort_mean & TR & 505 & 4.0050 & 1.37109 & 0.06101 \\
& UK & 522 & 4.6523 & 0.99352 & 0.04349 \\
social_mean & TR & 504 & 4.3591 & 1.43584 & 0.06396 \\
& UK & 522 & 5.0670 & 0.94944 & 0.04156 \\
facilitating_mean & TR & 508 & 3.3947 & 1.47170 & 0.06530 \\
& UK & 522 & 4.5951 & 0.99669 & 0.04362 \\
intention_mean & TR & 509 & 4.2318 & 1.50272 & 0.06661 \\
& UK & 522 & 5.5805 & 0.62362 & 0.02730 \\
& TR & 506 & 3.9888 & 1.46791 & 0.06526 \\
\hline
\end{tabular}


Table 7 Independent Samples Test

\begin{tabular}{|c|c|c|c|c|c|c|c|c|}
\hline & & \multicolumn{2}{|c|}{$\begin{array}{l}\text { Levene's Test for } \\
\text { Equality of Variances }\end{array}$} & \multicolumn{5}{|c|}{$t$-test for Equality of Means } \\
\hline & & $\mathrm{F}$ & Sig. & $\mathrm{t}$ & $d f$ & $\begin{array}{l}\text { Sig. } \\
\text { (2-tailed) }\end{array}$ & $\begin{array}{l}\text { Mean } \\
\text { Difference }\end{array}$ & $\begin{array}{l}\text { Std. Error } \\
\text { Difference }\end{array}$ \\
\hline \multirow[t]{2}{*}{ use behavior } & $\begin{array}{l}\text { Equal variances } \\
\text { assumed }\end{array}$ & 137.779 & .000 & 14.224 & 1006 & .000 & 1.493 & .105 \\
\hline & $\begin{array}{l}\text { Equal variances } \\
\text { not assumed }\end{array}$ & & & 14.037 & 844.231 & .000 & 1.493 & .106 \\
\hline \multirow[t]{2}{*}{ perf_mean } & $\begin{array}{l}\text { Equal variances } \\
\text { assumed }\end{array}$ & 52.233 & .000 & 8.685 & 1025 & .000 & .64735 & .07454 \\
\hline & $\begin{array}{l}\text { Equal variances } \\
\text { not assumed }\end{array}$ & & & 8.640 & 917.151 & .000 & .64735 & .07492 \\
\hline \multirow[t]{2}{*}{ effort_mean } & $\begin{array}{l}\text { Equal variances } \\
\text { assumed }\end{array}$ & 110.381 & .000 & 9.346 & 1024 & .000 & .70792 & .07575 \\
\hline & $\begin{array}{l}\text { Equal variances } \\
\text { not assumed }\end{array}$ & & & 9.282 & 867.997 & .000 & .70792 & .07627 \\
\hline \multirow[t]{2}{*}{ social_mean } & $\begin{array}{l}\text { Equal variances } \\
\text { assumed }\end{array}$ & 85.556 & .000 & 15.364 & 1028 & .000 & 1.20046 & .07813 \\
\hline & $\begin{array}{l}\text { Equal variances } \\
\text { not assumed }\end{array}$ & & & 15.287 & 888.371 & .000 & 1.20046 & .07853 \\
\hline \multirow[t]{2}{*}{ facilitating_mean } & $\begin{array}{l}\text { Equal variances } \\
\text { assumed }\end{array}$ & 362.202 & .000 & 18.903 & 1029 & .000 & 1.34863 & .07134 \\
\hline & $\begin{array}{l}\text { Equal variances } \\
\text { not assumed }\end{array}$ & & & 18.736 & 674.403 & .000 & 1.34863 & .07198 \\
\hline \multirow[t]{2}{*}{ intention_mean } & $\begin{array}{l}\text { Equal variances } \\
\text { assumed }\end{array}$ & 29.800 & .000 & 14.032 & 1026 & .000 & 1.19064 & .08485 \\
\hline & $\begin{array}{l}\text { Equal variances } \\
\text { not assumed }\end{array}$ & & & 13.997 & 989.282 & .000 & 1.19064 & .08506 \\
\hline
\end{tabular}

Turkey and the United Kingdom were administered with a questionnaire asking them to assess the VLE used in their respective universities.

The study determined that the students' use behavior and behavioral intention to use towards the VLE differed between the samples in Turkey and the United Kingdom. Students in the United Kingdom displayed a higher level of intention to use and use frequency than the students in Turkey. Although both the universities in Turkey and the United Kingdom (Sakarya University and Leeds University) began transitioning to virtual learning environments at approximately the same period, British students exhibited greater ease in adopting these systems, possibly because these students have better access to the internet and digital technology than Turkish students. Moreover, significant differences were clearly observed between the two countries not only in terms of the behavioral intention to use and use behavior, but also in terms of the relative effects of the factors that influence this intention and behavior.

Statistical analyses revealed that the effect of performance expectancy on behavioral intention was significant for both the samples in Turkey and the United Kingdom, although in the United Kingdom sample, performance expectancy had a relatively greater effect on behavioral intention. A more favorable student perception concerning the benefits of the VLE and its effect on their academic performance and grades was associated with a greater willingness to use this system. The effort expectancy was observed to have a greater effect on behavioral intention in the sample from Turkey. Turkish students placed greater importance on the ease of learning and using a system. On the 
other hand, for British students, it was noted that the ease of use of a system did not have a considerable effect on their intention to use. Similarly, in the sample from Turkey, social influence had a stronger effect on behavioral intention. In fact, social influence was identified in the sample from Turkey as the variable with the strongest effect on the intention to use. Having friends who thought that they should use the VLE, as well as having lecturers who assist with the use of the VLE, positively affected the students' behavioural intention to use. In the sample from the United Kingdom, the factor with the strongest effect on behavioral intention was the students' belief that the system would contribute to their academic performance.

It was observed that the antecedents of the use behavior exhibited different characteristics between the two samples. A general evaluation of the results from the two regression models used within the scope of the study showed that in the United Kingdom sample, use behavior was mainly influenced by behavioral intention and by performance expectancy, effort expectancy and social influence, which are the antecedents of behavioral intention. This means that individuals in this sample were more willing to use a technology depending on the extent the conditions became conducive for its use. However, one noteworthy aspect concerning this sample was that external supportive conditions had a greater explanatory power than behavioral intention. Concerning the sample from Turkey, the analysis revealed a weak relationship between intention and use behavior, which was rendered insignificant -or, in other words, masked - when the external factors that affect use were taken into account. This finding indicates that for Turkey, the most important factor or approach that needs be considered for promoting the use of virtual learning environments is increasing the amount of resources available for the use of these systems, and enhancing the level of knowledge concerning these systems. In addition to these analyses the differences between two countries in terms of behavioral intention and use behavior are tested and significant differences were observed. As a result, the UTAUT model is valid for a virtual learning environment both in Turkey and in the UK on the basis of the two universities.

\section{Limitations and future directions}

The study had a number of limitations. First of all, the study is based on the comparison of two countries, and attempts to describe the acceptance and use of a virtual learning environment in higher education exclusively within the context of these countries. However, both samples representing these two countries consisted exclusively of students from two universities, one in Turkey and the other in the United Kingdom. While both countries have a large number of universities that utilize virtual learning environments in higher education, time-and cost-related constraints limited the number of universities that could be accessed for the purposes of this study. For this reason, when evaluating the study results, it is important to bear in mind that these results are not generalizable to the entire university student population in both countries.

Despite the fact that the study was conducted in two countries that differ significantly from one another with respect to culture, culture in itself was not included as a factor into the study model. There is consequently a need for more comprehensive studies that take into account the effect of culture on the use of technology, and which 
examine the relationship between culture and technology use. We also believe that performing comparisons with countries in the same region as Turkey will yield interest results. In addition, based on the study findings regarding the virtual learning environments presented by Turkish universities, it might also be possible to evaluate and explain the acceptance and use of other technologies used in educational institutions. Furthermore, considering Turkey's large geographical area, it might also be interesting to assess whether there is any variation in the acceptance and use of technologies in higher education with respect to region.

\section{Abbreviations}

IDT: The innovation diffusion theory; MM: Motivational model; MPCU: The model of personal computer utilization; SCT: Social cognitive theory; TAM: Technology Acceptance Model; TAM2: Technology Acceptance Model 2; TAM3: Technology Acceptance Model 3; TPB: The theory of planned behavior; TR: Turkey; TRA: Theory of reasoned action; UK: United Kingdom; UTAUT: Unified theory of acceptance and use of technology; VLE: Virtual learning environment

\section{Acknowledgements}

We would like to thank the instructors at the University of Leeds and Sakarya University who helped us with data collection and all the students who participated in our survey.

Based on virtual learning systems which possess similar features, the research focuses on the system acceptance and utilization behaviours of the students from two public universities from Turkey and the UK through employing and pre-tested and accepted model in the literature. Hence, we believe that this study fits well into the aims and scope of International Journal of Educational Technology in Higher Education.

\section{Authors' contributions}

ÖEK is responsible for approximately $90 \%$ of the experimental work and paper authoring. Both authors read and approved the final manuscript.

\section{Competing interests}

The authors declare that they have no competing interests. The authors also confirm that the content of the manuscript has not been published or summited for publication to any other outlets.

\section{Publisher's Note}

Springer Nature remains neutral with regard to jurisdictional claims in published maps and institutional affiliations.

\section{Author details}

${ }^{1}$ Computer Programming Department, Yalova University, Yalova Meslek Yüksekokulu, Baglarbasi M. Safranyolu C., 77100, Merkez, Yalova, Turkey. ${ }^{2}$ Informatics Department, Marmara University, Nişantaşı Kampüsü Büyükçiftlik Sokak No:6, Nişantaşı, 34365, Şişli, İstanbul, Turkey.

Received: 22 March 2017 Accepted: 11 June 2017

Published online: 23 October 2017

\section{References}

Ajzen, I. (1985). From intentions to actions: A theory of planned behavior. In J. Kuhl \& J. Beckmann (Eds.), Action control from cognition to behavior (pp. 11-39). New York: Springer.

Ajzen, I. (2005). Attitudes, personality and behavior. New York: McGraw-Hill.

Ajzen, I., \& Fishbein, M. (1969). The prediction behavioral intentions in a choice situation. Journal of Experimental Social Psychology, 5, 400-416.

Ajzen, I., \& Fishbein, M. (1970). The prediction behavior from attitudinal and normative variables. Journal of Experimental Social Psychology, 6, 466-487.

Ajzen, I., \& Madden, T. J. (1986). Prediction of goal-directed behavior: attitudes, intentions, and perceived behavioral control. Journal of Experimental Social Psychology, 22, 453-474.

Al-Gahtani, S. S., Hubona, G. S., \& Wang, J. (2007). Information technology (IT) in Saudi Arabia: culture and the acceptance and use of IT. Information \& Management, 44(8), 681-691.

Al-Senaidi, S., Lin, L., \& Poirot, J. (2009). Barriers to adopting technology for teaching and learning in Oman. Computers \& Education, 53(3), 575-590.

Chau, P. Y. K. (1996). An empirical assessment of a modified technology acceptance model. Journal of Management Information Systems, 13.2, 185-204.

Chau, P. Y. K., \& Hu, P. J. (2001). Information technology acceptance by individual professionals: a model comparison approach. Decision Science, 32(4), 699-719.

Chiu, C. M., \& Wang, E. T. (2008). Understanding Web-based learning continuance intention: the role of subjective task value. Information \& Management, 45(3), 194-201.

Davis, F. D. (1985). A technology acceptance model for empirically testing New End-user information systems: theory and results (Unpublished PhD Thesis). Massachusetts: Institute of Technology.

Davis, F. D. (1989). Perceived usefulness, perceived ease of use, and user acceptance of information technology. MIS Quarterly, 13-3, 319-340. 
Davis, F. D., Bagozzi, R. P., \& Warshaw, P. R. (1989). User acceptance of computer technology: a comparison of Two theoretical models. Management Science, 35(8), 982-1003.

Diño, M. S., \& de Guzman, A. B. (2015). Using partial least squares (PLS) in predicting behavioral intention for telehealth use among Filipino elderly. Educational Gerontology, 41(1), 53-68.

Dulany, D. E. (1967). Awareness, rules, and propositional control: a confrontation with S-R behavior theory. In D. Horton \& T. Dixon (Eds.), Verbal behavior and S-R behavior theory. Englewood Cliffs: Prentice-Hall.

Fishbein, M., \& Ajzen, I. (1975). Belief, attitudes, intention, and behavior. An introduction to theory and research. Massachussets: Addison-Wesley.

Hou, C. K. (2014). Exploring the user acceptance of business intelligence systems in Taiwan's electronics industry: applying the UTAUT model. International Journal of Internet and Enterprise Management, 8(3), 195-226.

Igbaria, M., Guimaraes, T., \& Davis, G. B. (1995a). Testing the determinants of microcomputer usage via a structural equation model. Journal of Management Information Systems, 11(4), 87-114.

Igbaria, M., Livari, J., \& Maragahh, H. (1995b). Why Do individuals use computer technology? A Finnish case study. Information \& Management, 29, 227-238.

Im, l., Hong, S., \& Kang, M. S. (2011). An international comparison of technology adoption: testing the UTAUT model. Information \& management, 48(1), 1-8.

Kaba, B., \& Touré, B. (2014). Understanding information and communication technology behavioral intention to use: Applying the UTAUT model to social networking site adoption by young people in a least developed country. Journal of the Association for Information Science \& Technology, 65(8), 1662-1674.

Lee, I., Choi, B., Kim, J., \& Hong, S. J. (2007). Culture-technology fit: effects of cultural characteristics on the postadoption beliefs of mobile internet users. International Journal of Electronic Commerce, 11(4), 11-51.

Lee, Y., Kozar, K. A., \& Larsen, K. R. T. (2003). The technology acceptance model: past, present, and future. Communications of the Association for Information Systems, 12(50), 752-780.

Legris, P., Ingham, J., \& Collerette, P. (2003). Why Do people use information technology? A critical review of the technology acceptance model. Information \& Management, 40(3), 191-204.

Lin, C. P., \& Anol, B. (2008). Learning online social support: an investigation of network information technology based on UTAUT. Cyber Psychology\& Behavior, 11(3), 268-272.

Magsamen-Conrad, K., Upadhyaya, S., Joa, C. Y., \& Dowd, J. (2015). Bridging the divide: using UTAUT to predict multigenerational tablet adoption practices. Computers in Human Behavior, 50, 186-196.

McCoy, S., Galetta, D. F., \& King, W. R. (2007). Applying TAM across cultures: the need for caution. European Journal of Information Systems, 16, 81-90.

Martinez-Torres, M. R., Marin, S. L. T., Garcia, F. B., Vazguez, S. G., Oliva, M. A., \& Torres, T. (2008). A technological acceptance of E-learning tools used in practical and laboratory teaching, according to the European higher education area. Behaviour\& Information Technology, 27(6), 495-505.

Nistor, N., Lerche, T., Weinberger, A., Ceobanu, C., \& Heymann, O. (2014). Towards the integration of culture into the Unified Theory of Acceptance and Use of Technology. British Journal of Educational Technology, 45(1), 36-55.

Premkumar, G., Ramamurthy, K., \& Liu, H.-N. (2008). Internet messaging: an examination of the impact of attitudinal, normative and control belief systems. Information \& Management., 45, 451-457.

Raaij, E. M., \& Schepers, J. J. L. (2008). The acceptance and use of a virtual learning environment in China. Computers \& Education, 50, 838-852.

Robey, D. (1979). User attitudes and management information system use. The Academy of Management Journal, 22(3), 527-538.

Rogers, E., \& Shoemaker, F. F. (1971). Communication of innovations: a cross-cultural approach. New York: Free Press.

Schewe, C. D. (1976). The management information system user: an exploratory behavioral analysis. The Academy of Management Journal, 19(4), 577-590.

Sheppard, B., Hartwick, J., \& Warshaw, P. R. (1988). The theory of reasoned action: a meta-analysis of past research with recommendations for modifications and future research. Journal of Consumer Research, 15(3), 325-343.

Srite, M., Thatcher, J. B., \& Galy, E. (2008). Does within-culture variation matter? An empirical study of computer usage. Journal of Global Information Management, 16(1), 1-25.

Sumak, B, Polančič, G.\&Heričko, M. (2010) An empirical study of virtual learning environment adoption using UTAUT. Mobile, Hybrid, and On-Line Learning, 2010.ELML'10.Second International Conference on. (pp 17-22). IEEE

Sun, H., \& Zhang, P. (2006). The role of moderating factors in user technology acceptance. International Journal of Human-Computer Studies, 64(2), 53-78.

Taiwo, A. A., \& Downe, A. G. (2013). The theory of user acceptance and use of technology (UTAUT): a meta-analytic review of empirical findings. Journal of Theoretical \& Applied Information Technology, 49(1), 48-58.

Taylor, S., \& Todd, P. A. (1995). Understanding information technology usage: a test of competing models. Information Systems Research, 6(2), 144-176.

Tornatzky, L. G., \& Klein, K. J. (1982). Innovation characteristics and innovation adoption-implementation: a meta-analysis of findings. IEEE Transactions on Engineering Management, 29(1), 28-45.

Turan, A. H., \& Çolakoğlu, B. E. (2008). Yüksek Öğrenimde Öğretim Elemanlarının Teknoloji Kabulü ve Kullanımı: Adnan Menderes Üniversitesinde Ampirik Bir Değerlendirme. Doğuş Üniversitesi Dergisi, 9(1), 106-121.

Usluel, Y. K., Aşkar, P., \& Baş, T. (2008). A structural equation model for ICT usage in higher education. Educational Technology \& Society, 11(2), 276-273.

Venkatesh, V., \& Bala, H. (2008). Technology acceptance model 3 and a research agenda on interventions. Decision Sciences, 39(2), 273-315.

Venkatesh, V., \& Davis, F. D. (2000). A theoretical extension of the technology acceptance model: four longitudinal field studies. Management Science, 46(2), 186-204.

Venkatesh, V., Morris, M. G., Davis, G. B., \& Davis, F. D. (2003). User acceptance of information technology: toward a unified view. MIS Quarterly, 27(3), 425-478.

Wang, Y. S., \& Shih, Y. W. (2009). Why do people use information kiosks? A validation of the Unified Theory of Acceptance and Use of Technology. Government Information Quarterly, 26(1), 158-165. 
Wang, Y. S., Wu, M. C., \& Wang, H. Y. (2009). Investigating the determinants and age and gender differences in the acceptance of mobile learning. British Journal of Educational Technology, 40(1), 92-118.

Wejnert, B. (2002). Integrating models of diffusion of innovations: a conceptual framework. Annual Review of Sociology, $28,297-326$.

Zaremohzzabieh, Z., Samah, B. A., Omar, S. Z., Bolong, J., \& Mohamed Shaffril, H. A. (2014). Fisherman's acceptance of information and communication technology integration in Malaysia: exploring the moderating effect of age and experience. Journal of Applied Sciences, 14(9), 873-882.

\section{Submit your manuscript to a SpringerOpen ${ }^{\circ}$ journal and benefit from:}

- Convenient online submission

- Rigorous peer review

- Open access: articles freely available online

- High visibility within the field

- Retaining the copyright to your article

Submit your next manuscript at $\boldsymbol{s p r i n g e r o p e n . c o m ~}$ 